\title{
Management of right ventricular outflow tract obstruction: Evolution to revolution
}

\section{Gewillig* and S.C. Brown ${ }^{\#}$}

*Paediatric Cardiology, University Hospitals Leuven, Belgium

\# University of the Free State, South Africa

Address for correspondence:

Marc Gewillig

University Hospital Gasthuisberg

Herestraat 49

B 3000 Leuven

Belgium

Email:

marc.gewillig@uzleuven.be

\section{INTRODUCTION}

Until recently, surgery has been the only definitive treatment for the management of right ventricular outflow tract obstruction (RVOTO). However, a considerable number of these patients will subsequently develop right heart and outflow tract dysfunction and will require pulmonary valve replacement (PVR). The introduction of percutaneous pulmonary valve implantation (PPVI) has opened up new avenues of treatment for this group of patients. PPVI has been proven to be effective and safe with low complication rates. ${ }^{(1-3)}$ A notable advantage is the avoidance of openheart surgery and cardiopulmonary bypass combined with short hospital stays.

In order to understand the complexities involved in these conditions, the management of tetralogy of Fallot (ToF) can be considered as a classical example of development of RVOTO management strategies. The historical progression of management needs closer inspection.

\section{EVOLUTION OF TREATMENT FORTETRALOGY OF FALLOT}

Tetralogy of Fallot is the most common cyanotic congenital heart lesion accounting for 5 - $6 \%$ of all congenital heart lesions. ${ }^{(4)}$ Natural history studies show that, when left untreated, about half of chil-

\section{ABSTRACT}

Percutaneous pulmonary valves have opened up new avenues of treatment in patients requiring pulmonary valve replacement. The management of tetralogy of Fallot demonstrated the evolution of treatment: from palliative care to modern day early complete surgical repair. Use of trans-annular patches to treat right ventricle outflow obstruction gave rise to significant pulmonary regurgitation. Clinicians considered this a benign condition until, three decades later patients started dying unexpectedly. Surgical pulmonary valve replacement was the only treatment, but these showed dysfunction after some years. Clear guidelines for intervention do not exist. Current guidelines recommend treatment at upper limits of tolerance. Arguments for earlier intervention are presented, but none of the guidelines have been scientifically validated. SAHeart 20|4; 1 :12-16

dren die in early infancy and the remainder die at a mean age of 12.3 years. ${ }^{(5,6)}$ The advent of the Blalock shunt in the mid 1940s gave rise to the first palliative procedures in these children. This led to improved survival, but actuarial survival after 25 years in patients with all forms of palliative systemic to pulmonary artery shunts was in the region of $50 \%$ and quality of life was considered limited in $67 \%$ of these. ${ }^{(7)}$ A new era was initiated when Lillehei performed the first successful ToF repair in 1954.(8)

RVOTO following initial repair presented a significant challenge during this period. This gave rise to the widespread use of the trans annular patch (TAP) - up to $75 \%$ by the 1980 s. ${ }^{(9,10)}$ These right ventricular outflow tracts dilated markedly over time and gave rise to pulmonary regurgitation (PR). PR was initially considered a benign condition and clinicians largely ignored it. However, after 3 - 4 decades, unexpected episodes of cardiac deaths, dysrhythmias and right ventricular dysfunction were observed in these patients. Clinicians suddenly realised that PR is anything but an innocent condition.

In the current era emphasis has shifted to reparative surgery in early infancy and mortality has decreased too with operative mor- 
talities as low as $2 \% .^{(11,12)}$ While the risk of surgery has declined, TAP is still necessary in some neonates. Current surgical strategies aim to minimise the use of the TAP, but early repair regularly requires aggressive outflow tract reconstruction in infants with significant RVOTO. ${ }^{(13)}$

\section{EFFECTS OF SIGNIFICANT PR}

It is now well established that the haemodynamic substrate consisting of a dilating RVOT with resultant PR after reparative surgery in ToF patients is a major determinant of adverse outcomes. Although clinically "asymptomatic", long-term follow-up studies show accumulating morbidity and mortality. Studies show that excess mortality persist for more than 30 years after surgery with mortality ratios ranging from 309\% - 714\% and is clearly associated with the use of a TAP.(14) Sudden cardiac death has been reported in up to $6 \%$ of patients late after repair and has been estimated to occur at a rate of $0.2 \%$ per year..$^{(14-18)}$ Dysrhythmias are common in patients with PR and consist of atrial tachyarrhythmias in up to $30 \%$ and high grade ventricular tachycardias in $5-10 \%$ of patients. ${ }^{(16,19)}$ Gatzoulis identified a prolonged QRS $\geq 180 \mathrm{~ms}$ as a risk factor for ventricular tachycardia and sudden death. ${ }^{(20)}$ Additional problems include cardiac failure and right heart dilation in up to $29 \%$ of patients with isolated PR. ${ }^{(21)}$ Exercise intolerance with reduced oxygen uptake is also common in patients with dilated outflow tracts and PR. ${ }^{(19,22)}$

\section{MANAGEMENT OF PR}

Surgical pulmonary valve replacement has been the mainstay of treatment for patients with significant PR. Since their introduction in the early sixties, homografts have been the gold standard for PVR. ${ }^{(23)}$ Several other bioprosthetic valves are used, but still have to be proven equivalent to homografts. ${ }^{(24)}$

However, durability of homografts is not ideal and homograft degeneration after 10 years was observed in up to $46 \%$ of patients older than 10 years at implant; in younger patients degeneration was even more common: $65 \%$ after 5 years. ${ }^{(25,26)}$ Freedom from re-operation varies (see Table I) with rates of $97 \%$ at I year to on average $52 \%-70 \%$ and $31 \%$ after 10 and 15 years, respectively. ${ }^{(24,27-29)}$ It should be pointed out that follow-up in most studies was not ideal and more frequent follow-up would likely have shortened the event free periods.
It has been projected that the average patient may thus require up to 5 operations during a normal lifespan, each with accumulative morbidity and reduction in life expectancy. As a result, clinicians tend to delay surgery as long as possible in order to reduce the number of surgeries. This wait and watch strategy has been criticised and studies have shown that right ventricular recovery after PVR may be compromised. ${ }^{(30)}$

\section{TIMING OF SURGERY}

The ideal timing of PVR remains challenging and controversial. Although guidelines for indication of PVR have been proposed, indications are vague and ambiguous. The most common are: patients becoming symptomatic, increasing exercise intolerance, arrhythmias, development of moderate or severe tricuspid valve regurgitation, stenosis with right ventricular pressure more than $60 \%$ of systemic and volumetric criteria with right ventricular end-diastolic volume (RVEDV) $\geq 170 \mathrm{ml} / \mathrm{m}^{2}$ or systolic volume of $\geq 85 \mathrm{ml} / \mathrm{m}^{2}$ (19)

\section{LIMITATIONS OF CURRENT CRITERIA FOR PVR}

It should be noted that current criteria have not unequivocally been validated to prolong life and preserve right ventricular function. Exercise capacity, symptoms and the usual echocardiographic assessments have been shown to be inconsistent and do not correlate with the degree of right heart dysfunction. Magnetic resonance imaging (MRI) remains the gold standard for evaluation of right ventricular volumes. ${ }^{(31)}$ However, studies consist of small numbers, include heterogeneous RVOT substrates and none assessed effect on life-expectancy. Lee showed that a right ventricular end-diastolic cut-off value above $163 \mathrm{~m} / / \mathrm{m}^{2}$ before PVR was unlikely to result in "normalisation" of right ventricular end-diastolic volumes. ${ }^{(24)}$ In a meta-analysis of adult and paediatric studies, Cheung observed that none of the studies reported complete normalisation of the RVEDV. (32) They also noticed that

TABLE I: Pulmonary homografts: Freedom from re-intervention

\begin{tabular}{|l|c|c|c|c|c|c|}
\hline & \multicolumn{5}{c}{ Freedom from re-intervention (\%) } \\
\hline Series & Number(n) & Published & I year & 5 years & 10 years & 15 years \\
\hline Kim & 112 & 2011 & 97 & 77 & 35 & \\
\hline Dearnari & 1095 & 2003 & & & 55 & 32 \\
\hline Stark & 656 & 1998 & & 84 & 58 & 31 \\
\hline
\end{tabular}


although surgical PVR improved right ventricular volumes, QRS duration remained largely unchanged. Interestingly, Frigiola reported normalisation of RVEDV when using a relatively aggressive PVR policy in younger patients of right ventricular volumes below $150 \mathrm{ml} / \mathrm{m}^{2}$.(33) In a recent study consisting of I 085 patients after repair of tetralogy of Fallot, the group with the most favourable outcomes had only mildly dilated right ventricles with pulmonary annulus $z$-score $<0.5$ at the age of final analysis and a RVEDV of $101 \pm 26 \mathrm{ml} / \mathrm{m}^{2}$ indicating that near normal haemodynamic volumes are associated with improved survival. ${ }^{(34)}$

One should also take into account the fact that in patients with TAP, the MRI right ventricular volumetric measurements include the volume of the dilated RVOT and TAP. Since this is usually excised during surgical PVR, an exaggerated impression of improvement in right ventricular volumes post-surgery may be obtained. Furthermore, published literature only considers the upper limits of volumetric tolerance but none have assessed the lower limits where electromechanical remodelling becomes irreversible. This is an important concept: in patients with pulmonary regurgitation, abnormalities of right ventricular deformation indices (strain) were found despite normal global right ventricular function on MRI.(35) Furthermore, in a study in elite cyclists a disproportionate incidence of dysrhythmias and sudden death was described. Electrical dysfunction was ascribed to right ventricular dilation that occurred because of the huge volume load on the right heart during frequent peak exercise in these athletes. It should be noted that the episodes occurred in all athletes in the absence of measurable right ventricular dysfunction. ${ }^{(36)}$

The right ventricle is not an isolated structure: it shares the interventricular septum with the left ventricle and current indications ignore demonstrable left ventricular dysfunction and dyssynchrony as a result of right heart dilation. ${ }^{(37-39)}$ Puranik showed that indexed right and left ventricular end-diastolic volumes were consistently higher and biventricular function lower in tetralogy patients when compared to patients with PR resulting from treatment of pure valvar pulmonary stenosis. ${ }^{(40)}$ They also identified RVOT dysfunction resulting from TAP as an important additional factor in determining left ventricular volume, function and long-term prognosis. Current guidelines generally do not take the left ventricle into account.
In summary, waiting for symptoms to appear before revalvulation is considered, will not lead to reversibility of right ventricular dysfunction. In a recent editorial Geva points out that our ability to prognosticate in these patients at present is poor and propose more liberal indications for PVR. ${ }^{(4)}$ It is thus evident that clinicians should look at new strategies where long term event free right ventricular (RV) function - both mechanical and electrical- is the ultimate goal and not any degree of recuperation of size or function, that still can and probably will be associated with late premature dysfunction.

\section{NEW STRATEGY OF PVR}

Ideal treatment for patients with ToF or conditions with similar physiology should consist of PVR with a valved conduit with negligible procedural risk, perfect long-term function, absence of need for valve replacement and normal life expectancy both in quantity and quality. This is the strategy we have adopted for the management of atrial septal defects (ASD): at an early age when mild right ventricle dilation is observed, the unfavourable natural history is predictable and the procedure can be carried out with negligible risk combined with excellent long-term results.

Treatment options for PVR have changed dramatically - percutaneous valves can now be implanted at low and progressively decreasing risk and, for the proper indications, are very competitive (compared to surgical conduits). ${ }^{(2,3,42-44)}$ The authors' current speculative strategy is demonstrated in Figure I. As mentioned, progressively dilating right ventricular outflow tracts have been shown to be a major risk factor for right and left ventricular dysfunction. Implanting a stent in the RVOT would arrest this increase in RVOT dimension and provide the substrate for a percutaneous valve. With current technology, such a window of opportunity presents itself at $8-12$ years of age before the RVOT becomes too dilated for secure stent fixation. An adult sized percutaneous valve can subsequently be implanted (aiming for z-score 0 - I). This can over time be followed by additional PPVI and/or surgical PVR (if required). The ultimate aim of this strategy would be to prolong life expectancy and preserve normal right ventricular function by intervention before irreversible right ventricular electro-mechanical dysfunction sets in. This brings us back to our initial ideal treatment strategy: instead of seeing how 


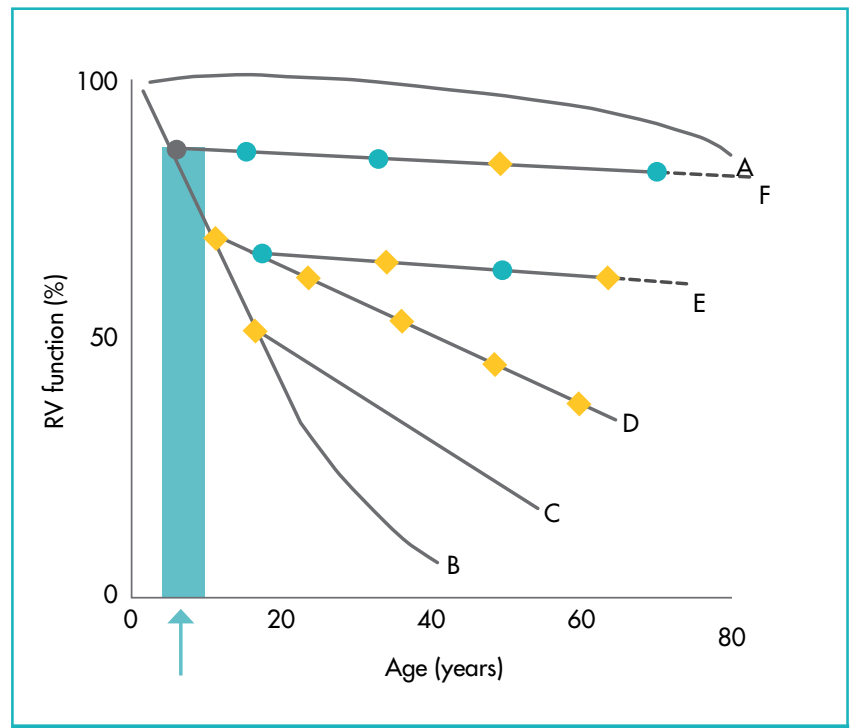

FIGURE I: Evolution of management strategies for

tetralogy of Fallot

Conceptual schematic of evolution of management strategies: ver-

tical axis represents global right heart function including regurgi-

tation, dilation, failure, electro-mechanical abnormalities, etc. Also

see text for full description of evolution of strategies. Blue arrow

indicates window of opportunity. Yellow diamonds indicate PVR

with surgical homograft. Solid circles indicate PVR with percutaneous

valved stent. The solid blue bar indicates stent at $8-12$ years

(window of opportunity).

A: Normal individual, B: Natural progression in patients with significant PR: decline in RV function with dysrhythmias in second decade of life, $C$ : Revalvulation when symptomatic: incomplete improvement, D: Strategy PVR with surgical homografts. Increased morbidity and mortality with every re-operation, some but incomplete recovery of right ventricular function, E: Strategy with PPVI: intervene earlier after first homograft and follow up with PPVI or surgical PVR over time. Intervene sooner, reduce number of surgeries and prolong life expectancy whilst preventing decline in RV function, F: Proposed new strategy: stent RVOT during window of opportunity before important RVOT dilation due to TAP sets in; PPVI early with adult sized valve. Follow up with another PPVI and later surgery. Aim is to extend lifespan and maintain RV function to as near "normal" as possible.

far you can allow the RV to be damaged before compromising lifespan and function in a patient, (risking premature deaths in many patients as happened with previous guidelines) aim for revalvulation as soon as an adult sized valve can be implanted, provided this happens at near zero risk and with long lasting valve durability (at the risk of underestimating complications of a valved stent in the RVOT during long term follow-up).

\section{LIMITATIONS OFTHIS STRATEGY}

It should be noted that the abovementioned strategy is debatable and also unproven at this stage: the outcome of such a strategy can only be expected in $3-4$ decades. Questions that remain include: will right ventricular function be preserved, will frequency of intervention be decreased and what effect will it have on life expectancy? Issues such as longevity of percutaneous pulmonary valves, susceptibility to endocarditis, age at intervention and immunological factors that have not yet been adequately answered may have an effect on the final outcome. ${ }^{(45)}$

\section{CONCLUSION}

Current indications for PVR are vague and consider only the upper limits of tolerance. We must remain critical: as clinicians we should not repeat the errors of the late 1980s when we assumed that any degree of PR would be well tolerated over a lifetime. As such, we must remain critical towards the current "guidelines" which have some logical background, but the jury is still out on their final long term value. Newer strategies have a different long-term aim: preserve right ventricular function and prolong lifespan. Good arguments exist to lower intervention thresholds. However, these remain unproven.

Declaration: Marc Gewillig is a proctor for Numed, Medtronic and Edwards. 


\section{REFERENCES}

I. Khambadkone S, Coats L, Taylor A, et al. Percutaneous Pulmonary valve implantation in humans: Results in 59 consecutive patients. Circulation 2005; 1 12: | $189-1197$.

2. Eichen A, Ewert $P$, Hager A, et al. Percutaneous pulmonary valve implantation: Two-center experience with more than 100 patients. Eur Heart J 2011;32: 1260-1265.

3. McElhinney DB, Hellenbrand WE, Zahn E, et al. Short- and medium-term outcomes after transcatheter pulmonary valve placement in the expanded US Melody Valve trial. Circulation 2010;122:507-516.

4. Van der Linde D, Konings EE, Slager MA, et al. Birth prevalence of congenital heart disease worldwide: A systematic review and meta-analysis. J Am Coll Cardiol 201 1;58:2241-7

5. Campbell M. Natural history of cyanotic malformations and comparison of all common cardiac malformations. Br Heart J 1972;34:3-8.

6. Bonchek L, Starr A, Sunderland O. Natural history of tetralogy in infancy: Clinical classification and therapeutic implications. Circulation 1973;48:392-97.

7. Presibitero P, D'Antonia P, Brusca A, et al. Prognosis of Fallot's tetralogy after palliative operations: 10 - 25 year follow-up. Paediatr Cardiol 1983:4: 175-82

8. Lillehei CW, Cohen M, Warden, et al. Intracardiac surgical correction of the tetralogy of Fallot, pentalogy of Fallot and pulmonary atresia defects; report of first ten cases. Ann Surg 1955;42:41 8-42

9. Touati GD, Vouhe PR, Amodeo A, et al. Primary repair of tetralogy of Fallot in infancy. J Thoracic Cardiovasc Surg 1990;99:396-402.

10. De Ruijter FT, Weenink I, Hitchkock FJ, et al. Right ventricular dysfunction and pulmonary valve replacement after correction of tetralogy of Fallot. Ann Thorac Surg 2002;73:1794-800

II. Stellin G, Milanesi O, Rubino M, et al. Repair of tetralogy of Fallot in the first 6 months of life: Transatrial versus transventricular approach. Ann Thorac Surg 1995;60:S588-91.

12. Karl TR, Sano S, Pornviliwan S, et al. Tetralogy of Fallot: Favourable outcome of nonneonatal transatrial, transpulmonary repair. Ann Thorac Surg 1992;54:903-7.

13. Norgard G, Gatzoulis MA, Moraes F, et al. Relationship between type of outflow tract repair and post-operative right ventricular diastolic physiology in tetralogy of Fallot. Implications for long-term outcome. Circulation 1996;94:3276-80.

14. Pokorski RJ. Long-term survival after repair of tetralogy of Fallot. J Insur Med 2000;32:89-92

15. Kavey RE, Blackman MS, Sondheimer HM. Incidence and severity of chronic ventricular dysrhythmias after repair of tetralogy of Fallot. Am Heart J 1982; 103(3):342-50

16. Villafañe J, Feinstein JA, Jenkins KJ, et al. Hot topics in tetralogy of Fallot. J Am Coll Cardiol. 20 I 3 Sep 26. doi:pii: S0735- I097(I 3)05379-5. I 0. I 0 I6/j.jacc.20 I 3.07. I 00 (Epub ahead of print)

17. Hickey EJ, Veldtman G, Bradley TJ, et al. Late risk of outcomes for adults with repaired tetralogy of Fallot from an inception cohort spanning 4 decades. Eur J Cardiothorac Surg. 2009:35:156-64.

18. Knott-Craig C], Elkins RC, Lane MM, et al. A 26-year experience with surgical management of tetralogy of Fallot: Risk analysis for mortality or late reintervention. Ann Thorac Surg. Aug 1998;66(2):506-II.

19. Zaragoza-Macias E, Stout KK. Management of pulmonic regurgitation and right ventricular dysfunction in the adult with repaired tetralogy of Fallot. Curr treat options Cardiovasc Med 2013;15:575-86.

20. Gatzoulis MA, Sommerville J, Redington AN. Mechanoelectrical interaction in tetralogy of Fallot, QRS prolongation relates to right ventricular size and predicts malignant ventricular arrhythmias and sudden death. Circulation 1995;92:231-7.

21. Shimazaki Y, Blackstone EH, Kirklin JW. The natural history of isolated congenital pulmonary valve incompetence: Surgical implications. Thorac Cardiovasc Surg. 1984;32:257-9

22. Giardini A, Specchia S, Tacy TA, et al. Usefulness of cardiopulmonary exercise to predict long-term prognosis in adults with repaired tetralogy of Fallot. Am J Cardiol. 2007:99: | 462-7.

23. Ross DN. Homograft replacement of the aortic valve. Lancet 1962;2:487

24. Lee C, Soo Park C, Lee C-H, et al. Durability of bioprosthetic valves in the pulmonary position: Long-term follow-up of 181 implants in patients with congenital heart disease. J Thorac Cardiovasc Surg 20 I I; I 42:35 I-8.
25. Boethig D, Goerler $\mathrm{H}$, Westhoff-Black M, et al. Evaluation of 188 consecutive homografts implanted in pulmonary position after 20 years. Eur J CardioThorac Surg 2007:32:133-142.

26. Karamlou T, Blackstone EH, Hawkins JA, et al. Pulmonary conduit working group for members of the congenital heart surgeon's society. Can pulmonary conduit dysfunction and failure be reduced in infants and children less than 2 years at implantation? J Thorac Cardiovasc Surg 2006;1 32:829-38.

27. Kim H, Dong-Man S, Hong Ju S, et al. Long term results of right ventricular outflow tract reconstruction with homografts. Korean J Cardiovasc Surg 20 I 1;44: 1 08-1 | 4

28. Stark J, Bull C, Stajevic M, et al. Fate of subpulmonary homograft conduits: Determinants of late homograft failure. J Thorac Cardiovasc Surg 1998; I15: 506-5I6.

29. Dearani JA, Danielson GK, Puga J. Late follow-up of I 095 patients undergoing operation for complex congenital heart disease utilising pulmonary ventricle to pulmonary artery conduits. Ann Thorac Surg 2003;75:399-4II.

30. Therrien J, Siu SC, McLaughlin PR, et al. Pulmonary valve replacement in adults late after repair of tetralogy of Fallot: Are we operating too late? I Am Coll Cardiol 2000;36:1670-5

31. Geva T. Repaired tetralogy of Fallot: The roles of cardiovascular magnetic resonance in evaluating pathophysiology and for pulmonary valve replacement decision support. J Cardiovasc Magn Reson 201 1;13:9-9.

32. Cheung EW, Wong WH, Cheung Y. Meta-analysis of pulmonary valve replacement after operative repair of tetralogy of Fallot. Am J cardiol 2010; 106:552-57.

33. Frigiola $A$, Tsang $\vee$, Bull $C$, et al. Biventricular response after pulmonary valve replacement for right ventricular outflow tract dysfunction. Is age a predictor of outcome? Circulation 2008; 1 18:S182-90.

34. Frigiola $A$, Hughes $M$, Turner $M$, et al. Physiological and phenotypic characteristics of late survivors of tetralogy of Fallot repair who are free from pulmonary valve replacement. Circulation 2013; | 28: | 86 |-68

35. Eyskens B, Brown SC, Claus $\mathrm{P}$, et al. The influence of pulmonary regurgitation on regional right ventricular function in children after repair of tetralogy of Fallot. Eur J Echocard 2010;1 1:341-345.

36. Heidbüchel $\mathrm{H}$, Hoogsteen J, Fagard $\mathrm{R}$, et al. High prevalence of right ventricular involvement in endurance athletes with ventricular arrhythmias. Eur Heart | 2003;24: | 473- 480.

37. Liang $X C$, Cheung EW, Wong SJ, et al. Impact of right ventricular volume overload on three-dimensional global left ventricular mechanical dyssynchrony after surgical repair of tetralogy of Fallot. Am J Cardiol 2008;102:1731-36.

38. Cheung EW, Liang XC, Lam WW, et al. Impact of right ventricular dilation on left ventricular myocardial deformation in patients after surgical repair of tetralogy of Fallot. Am J Cardiol 2009; 1 04: 1 264-70

39. Valente AM, Gauvreau K, Assenza GE, et al. Contemporary predictors of death and sustained ventricular tachycardia in patients with repaired tetralogy of Fallot in the INDICATOR cohort. Heart 2013 as 10.1 | 36/heartjnl-20 I3-304958.

40. Puranik $R$, Tsang $V$, Lurz $P$, et al. Long-term importance of right ventricular outflow tract patch function in patients with pulmonary regurgitation. J Thorac Cardiovasc Surg 2012; | 43: I 103-7.

4I. Geva T. Indications for pulmonary valve replacement in repaired tetralogy of Fallot. The quest continues. Circulation 2013;28: 1855-57.

42. Butera G, Milanesi $\mathrm{O}$, Spadoni I, et al. Melody transcatheter pulmonary valve implantation. Results from the registry of the Italian Society of Paediatric Cardiology. Catheter Cardiovasc Interv. Feb 20 I 3;8I (2):3 I0-6.

43. Brown DW, McElhinney DB, Araoz PA, et al. Reliability and accuracy of echocardiographic right heart evaluation in the US Melody valve investigational trial. J Am Soc Echocardiogr 2012;25:383-392.

44. Faza N, Kenny D, Kavinsky C, et al. Single-center comparative outcomes of the Edwards SAPIEN and Medtronic Melody transcatheter heart valves in the pulmonary position. Catheter Cardiovasc Interv. I Oct 2013;82:E535-4I.

45. Buber J, Bergesen I, Lock JE, et al. Bloodstream infections occurring in patients with percutaneously implanted bioprosthetic pulmonary valve. Circ Cardiovasc Interv 2013:6:301-310 